\title{
HOLMES ST. FORENSIC LAB \& EDUCATION CENTER (IDEA OF INTERIORITY THROUGH THE TRAIL OBSERVATION)
}

\author{
Rahmania Alaydrus* \\ *) Department of Architecture, University of Indonesia, Jl. Margonda Raya, Beji, \\ Pondok Cina, Depok City, and 16424, Indonesia \\ e-mail: nialaydrus@hotmail.com
}

\begin{abstract}
Humans are the most important thing in a space experience. Two important aspects of public space are the feelings of comfort and discomfort. That comfort or discomfort kind of feeling in the public space, are obviously inseparable from the acts of crime. Through such approaches, I undertake this studies and a research for design, to identify the sequence of trails autopoietic processes, holistically, when human come up against their discomfort, and in their existential space. So, that specific and particular boundary from the trail will come up as identity. Identity of the past turns out into such an idea to be designed. When the segments are legible as segment-by-segment, the processes will be holistically identified as a whole story. When the presence of a trail becomes a boundary, therein the trail will appear as the interiority.
\end{abstract}

Keywords: Interiority, Trail, Living Machine, Criminality, Identify

\section{INTRODUCTION}

The public spaces of a city, such as its streets, footpaths, waterfronts, parks, plazas, town squares and laneways give form to the ebb and flow of human exchange and interaction (Carr et al. 1992). They are often where people find some of the most stimulating, exciting and worthwhile experiences of their lives (Beattie and Lehmann 1994). Human beings become an important part of public space and the overall experience in it. As well as human with their own existential space experience. The existential space itself can be interpreted differently by every single human being, based on their own environment context. Come through memory, perception, meaning, and every point of view. Each person will be different, based on their own process of thinking. Every single process of thinking could be affected by their own experience, either the good one or the bad one. The way human interpret their environment (through space and place) are all different, based on their 
own immediate sensory experience and affected by every single experience that appears from their own past. The relationship between people and the environment is examined by focusing on how the physical and ambient stimuli (or features) of an environment affect behaviour and emotions (Mehrabian and Russel 1974). Especially from anything that can interfere their comfort zone. Either from natural disturbances or from other human, or for anything else in the scope of "public spaces". Human behavior, interaction and experiences in public space are believed to be the result of the "process of thinking" that are influenced by different "human being experience". "The continuity of human life in such a space which essentially consists of interior space (interior selves) and external space (exterior world), can also be defined as the embodiment of human existential space (Ponty, in Olkowski and Morley, 1999).

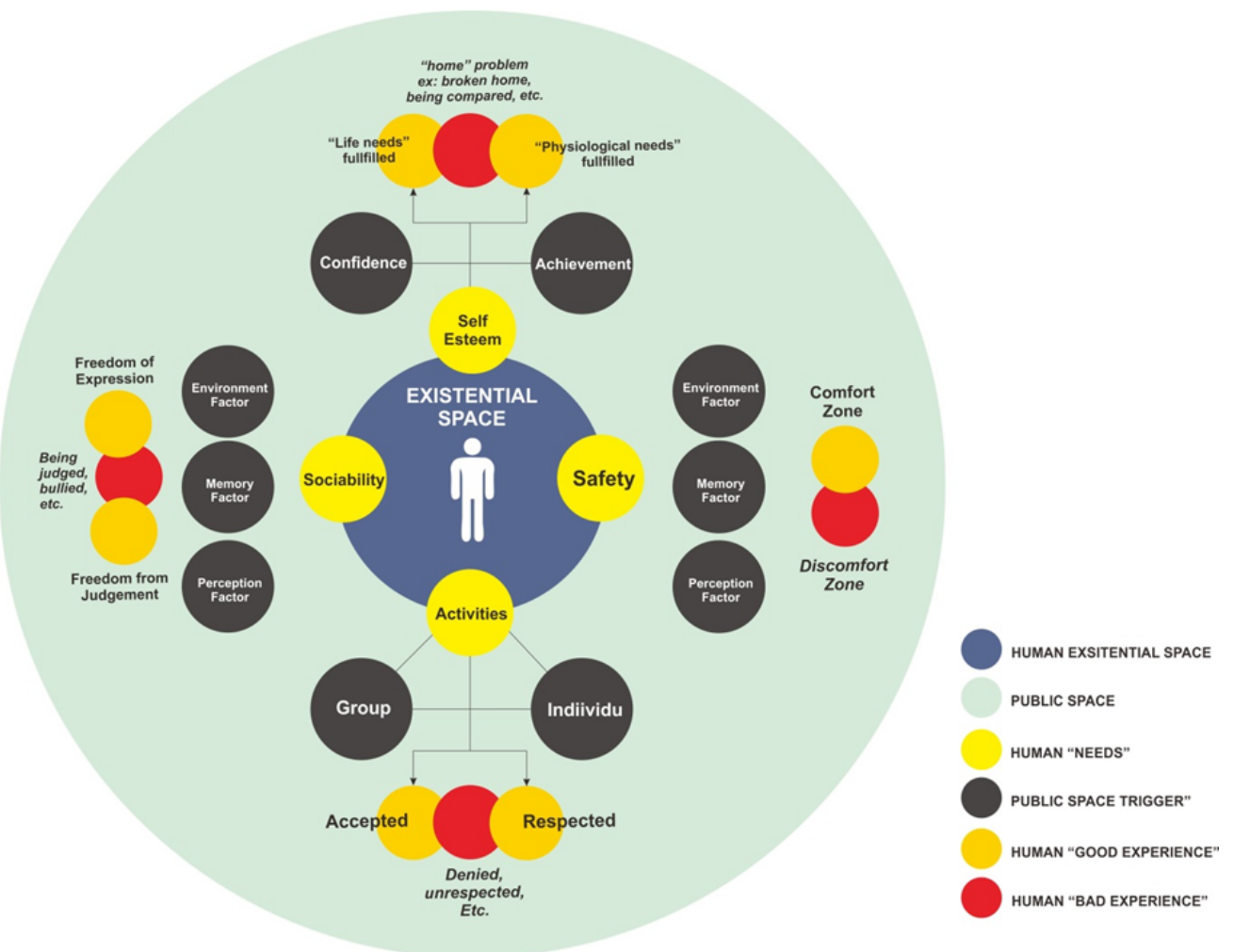

Figure 1. The Relation Between Human Being, Human Existential Space, and Public Space Source: Personal Work, 2017

Every human have their own existential space with some essential needs (Figure 1). And there will always be connection, between human existential space and public spaces. These might be physical, social, cultural, environmental, or even sensory connection. And that connection, will always influence their memory, either 
they remember or forget anything about their experience. "Human beings not only discern geometric patterns in nature and create abstract spaces in the mind; they also try to embody their feelings, images, and thoughts in tangible material." (Tuan, 1977). On the other hand, the public space itself is an "open space" that can be freely accessed, where each person or group can do activities together. Either at the same time, or at different times. Public spaces are inseparable from their environment.

Point of this study is all about human "safety needs" that affect human other needs such as self-esteem, sociability, etc. (Figure 1) This is about human comfort zone and discomfort zone in a public space. And even the comfort zone cannot be separated from crime. Many people tried to solve crime with forensic science. And this design of "Holmes St. Forensic Lab and Education Center" is related to the context of forensic study, using Trace Evidence Analysis approach. The study of this design is grounded in fundamental tracing concepts and techniques that are gathered from the natural environment experience and forensic science through a generative methodology of design.

Through this approach, I conduct this study and research as an idea for design, with the aim of:

1. To discover about human observation process while they are realizing something from their "past", in this "present" space, that affected by also "present" environment. That kind of thinking process, will initiate human beings as an identifiers. The identifiers of what they see will always be a "small part" of the other "whole" story.

2. To observe and identify the other process, when humans experience discomfort in their existential space

3. To read the trails as a "space boundaries", or the space that "look like a boundaries". The existential space is just a small part of the whole living system. These traces allow for a retrace of motion.

4. To find out the "interiority" inside humans experience, through the trails.

So that the "certain limit" of a trail, will be the identity of the living system in human discomfort experience. The trail will be legible as a part of the holistic story. Then we can see the wholeness.

\section{THEORY / RESEARCH METHODS}

\section{Metamorphosis of Space}

Living in a space does not make human being become an object among the other objects. Many processes are actually presence unconsciously when human experienced a discomfort, in their existential spaces. The ambient environment 
refers to the non-visual and non-physical elements of the built environment such as sound, smell, temperature and illumination.

This suggests that people's relationship with the environment ambience, especially when it comes to their bad experience. But mostly, they are unaware. Only the big part that appear. This is why a great sense of discomfort becomes the main reason for human being to trace their process of autopoietic system.

A living system reproduces itself. This self-reproduction they referred to as autopoietic. They defined the autopoietic system as a system that recursively reproduces its elements through its own elements. Central to the concept of autopoietic is the idea that the different elements of the system interact in such a way as to produce and re-produce the elements of the system. That is to say through its elements the system reproduces itself. (Luhmann, in Varela, 1974). That system can suddenly present some unconscious parts in anytime and anywhere, even from the very past accident.

\section{Human as Living Machine \& Environment as a Metaphor in Exfoliation Time}

Human do activities and living in their environment as a whole, by the whole it means every single thing is related. There is a relationship between every component. Even "time" is one of the most important component. Human live in a quite complicated space that full of risks but also full of opportunities, it's all related on how human survive. The idea that you need to think about something in order to be conscious of it is very illusive. You become "more conscious" when you stop identifying with your thoughts, and believing what you said is reality or becomes reality. Or anything surround you, reminds you about your bad experience, make you feels like it just happen, even though it's long gone. Through this process of thinking, human get the connection with environment, especially when it comes to remind human about their bad experience in their discomfort zone, or even in their comfort zone, and this comfort zone can suddenly turn out into discomfort zone.

"Environment", however, is not one with the "self", nor is it separated from the "self". This relationship between "environment" and "self" is not the same with that of two sides of the same coin (Maturana and Varela, 1974).

As long as an autopoietic system works, the region of "self" is continuously created within the topological space wherein "environment" emerges simultaneously with the production of "self". The moment the autopoietic system produces a "selfregion", "environment" penetrates into "self". So, the self stands independently by itself without knowing its surrounding environment. This is due to the work of "by itself". The "self" cannot recognize its surrounding, and so it finds its surrounding inexplicable, while it is ceaselessly penetrated by "environment". This relationship of the borderless penetration between an environment and "self" thus gives the 
"self" an impression of sheer complexity and incomprehensibility about its surrounding and also a borderless openness to its surrounding. (Maturana and Varela, 1974).

\section{The Presence of Flashback}

The autopoietic system will definitely continue, no matter what happen. God created this kind of system, to keeps the life of all beings balance. This system process is like wheels. These wheels will "go" with different speeds and stability, depending on many factors. The most obvious example to illustrate what is meant by an autopoietic living machine system is the biological cells of living things. One of the other real unconscious systems process is "the presence of flashback" through the correlation of eyes, mind, and perception response.

Three kinds of sensory response: First, an immediate physical response to stimulus; second, a response conditioned by prior knowledge of its source; and third, a response to stimulus as it has become identified in one's memory with particular time and place. (Malnar and Vodvarka, 2004).

Between human perceptual there is a processing process and the encoding process. Human mind start to do the processing process, when their bad memory comes around. Every interaction that occurs between human beings produces thoughts and perceptions, when involving some other human beings, objects or whatever that being around will bring back the memory, then result in an agreement that will generate and develop thought further.

"Mental images are an active, vital repository of information gathered through sensual experience, through sight, sound, smell, touch, and taste. (Malnar and Vodvarka, 2004). This process of reciprocity is then characterized by the process of autopoietic that occurs in a presence of flashback process. Human can remember each point of interaction with his environment into his memory.

\section{Beyond the Seen}

What is seen and seen is not always what the brain will accept, which processes something into a memory beyond what the human eye sees, the sense of space is unwittingly becoming a perception, a sense of security, a dream, a fear, a balance, a sense of home, movement, and others in presence.

An imagined place or state in which everything is unpleasant. A kind of feeling that present like the world got too many mind-pressures for human. A state in which everything are just "bad". A condition when the environment suddenly reminds every little thing. Through some kind of super-quick mind evolution, there is a lot of "signage". It's human unconscious mind obviously know what is "actually 
happen" supposed to be looked like, the color, shape, etc. For example, when a girl found a stone, her conscious mind will "see" it as a stone. Yes, in either color, shape, etc. it does look like stone. And it is stone. But her unconscious mind keeps bringing up everything that "unseen".

As we move mentally out to space, we also move either backward or forward in time. Physical movement across space can generate similar temporal illusions. (Malnar and Vodvarka, 2004).

\section{Sudden Recall}

Denial is a powerful and primitive defense mechanism. Someone who is dependent frightened and him or her selves the victim of abuse can remain silent and not even see or hear the abuse in order to maintain the desperately needed relationship with the abuser. Well, people do hear it and see it and fail to act. Identify a series of processes when humans experience discomfort in their existential space. Process and read traces as space boundaries, is just a small part of the tracing the living system that I use to recollect the case evidence (in this case, is bad experience). These traces allow for a retrace of motion.

Thus, a certain threshold of a trace will be the identity of a particular movement or action. And when movement after movement is read, it is hoped that the story of an event will be fully identifiable into a holistic whole of the story.

By starting to bring back the memory, even if just a single thing, it's unconsciously becomes the fulfillment of the main human needs. With such an approach, the architecture, minorities, and everything that relate, all becomes as if it presents with human-main perceptual (past or present).

When humans feel they don't have any space to live, in this phase, all human being will begin to try and do new things to the space that he occupies, humans will be able to get out of bounds just to create more space in order to achieve their sense of dwelling, so that they will own their "new" space. This is the first interiority approaches that designer use before the extension of a separation. A different perceptual have different properties in everybody's conscious mind, or at least different relations between eye, brain, and memory and the relationship with the object itself. But it's just the same when it turned out into human unconscious mind. So in the point of fact, it's all depends on human perception. "Image of the object" will consist of a diverse of many factors of symmetry and asymmetry of every individual. All entire set of these "signs" and will reflect the "image of the object asymmetry". At this point, if human had their bravery, they can continue to develop the trails seeking. Because at this point, their memory is slowly return. 
When human can feel and project their self against space, then space will turn into a place and the place will have a meaning. The presence of memory, it's because human can feel the space. The space becomes meaningful.

The most important force for a space that becomes 'place' is not determined by its form and its boundaries but rather is determined by how the quality of the space can be improved, and how humans interpret it. And at the end and it's all back to human. Indeed. Everything seems the idea is very simple. And most importantly, it's not objectively. But really it's just about the first perceptual that comes.

\section{RESULTS AND DISCUSSION}

\section{An Interconnected Part}

By going through the seeking process with several methods in reading the trace of autopoietic process, interiority is present and re-presented through "separations" by using layers, to see the interconnectedness and interaction of each segment or a small part from the whole incident. Understanding this holistically and interactively will be a very helpful method in viewing and interpreting various phenomena and reality that occurs in the searching process. Human will able to remember and compile some parts of the incident. This is a start to trace the entire trail by tracing method, part by part, layer by layer, scene by scene, etc.

\section{Trace}

Traces that appear will be part of that space. Through this approach, the designer conducts this study and research as a final project with the aim to see and know how the process of human observation while presenting $\&$ re-experiencing the past. The existence of the tracing process, will initiate human beings as an identifier. The identifiers of what they see are only a small part.

By using the tracing method (Figure 2), the designer begins to figure out where is the essence of space is in the context of interiority through the trace method. Also, trying to re-create the whole story. By using this trace method, the trail here will be seen as something "different" or "new" that obviously will look like an "alien" to every human being. But not for the one who experienced it. When doing a trace method, and find out a "boundaries", the interiority appear. Interiority is a "presence" form of the trail, in the space, with the presence of time. 

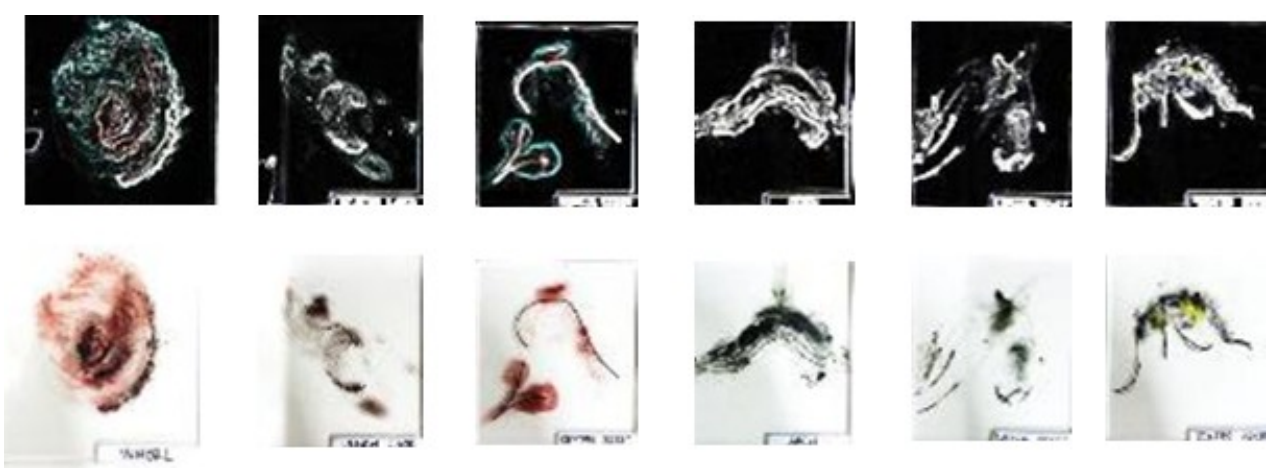

Figure 2. Sample, Breaking Down Every Single Part, From the Whole Trail. A sample made with Trace Method Source: Personal Work, 2016

Fingerprints are the smallest Identity of a trace that can help find important parts of the identification process. Especially if Rori finds fingerprints in a state of intact it can be used as a sign to find out the owner of a fingerprint, left behind in the event of a particular case is very profitable and very helpful identification process. And through fingerprints, identifiers can easily identify crimes that occur.

\section{Retrieval and Re-present}

Some techniques of "retrieval" or "re-identification" are by means of "something" is translated and read by the sample taken through scratches of fingerprints (Figure 3) in direct contact with the footprint and the trail area. By using the trace method and then recites it and re-unites it, I started to know that the line has 4 different qualities, first is direction (Direction) into 3 existing models, horizontal, vertical and diagonal. Next is, movements (Movement), every single lines have motion, third is a dimension (Dimension), direction and movement in line gives multifarious definition of dimension of field length or implication. The fourth is time, time being thus proved to be no more than a retrieval concept, a "recreate" process of measuring the "long-term" and "short-term" distance between one moment and another, it is similarly shown that by denying too tightly into the past moments, it doesn't mean every-single-part of the experience are reduced or curtailed. Time can be read in a line, and human are able to trying to remember the incident by using this kind of method. Of course that is because "distance is the concept of time". Kandinsky's theory helped me in "taking" and "re-drawing" samples of trails that were present. 

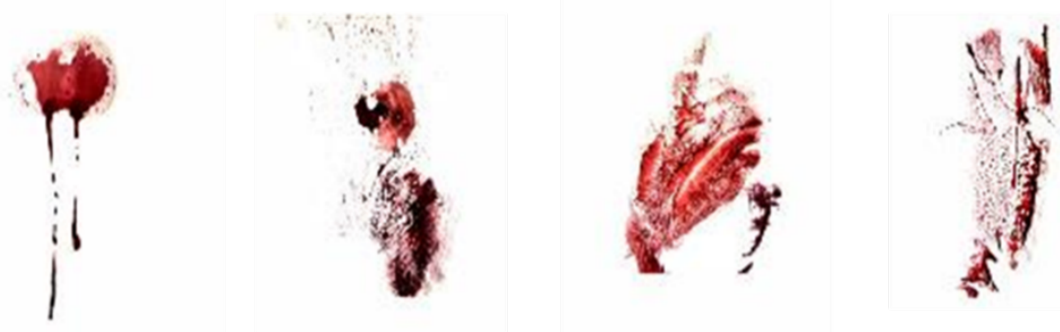

Figure 3. Samples made with Retrieval \& Re-present Method Source: Personal Work, 2016

\section{Recite and Unite}

After doing the analysis and see some samples that are represented and taken through Recite \& Unite method (Figure 4). Some important things to note in trace sampling with Recite \& Unite methods are:

a. Items that are identified as evidence, in the Recite \& Unite stages will be searched, reproduced, and carried as much as possible by the Recite method, to be able to bring valuable samples as the information for the identification process.

b. Moreover, in the Unite method itself, it will pay more attention to the above, of course, to relate the connectedness, unity as a whole, as a thorough evidence to be submitted to the investigator in exposing the crime, in line with the identification process.

c. The suspect that inevitably leave a trail / trace on the scene of the case and on the victim's body, any physical contact between the two subjects or even contacted with the environment, will always change direction, and the color change of each subject, although the displacement may be very small.

d. Items that tend to be general will be important as evidence when there are unusual characteristics. This can be proved by the Recite method, by bringing the smallest part

e. The more rare and unnatural a trace on the scene, the more important it functions as a crime evidence. Such as a trace samples can be taken using both methods from Trace Method and Recite \& Unite Method (Fig. 4). 

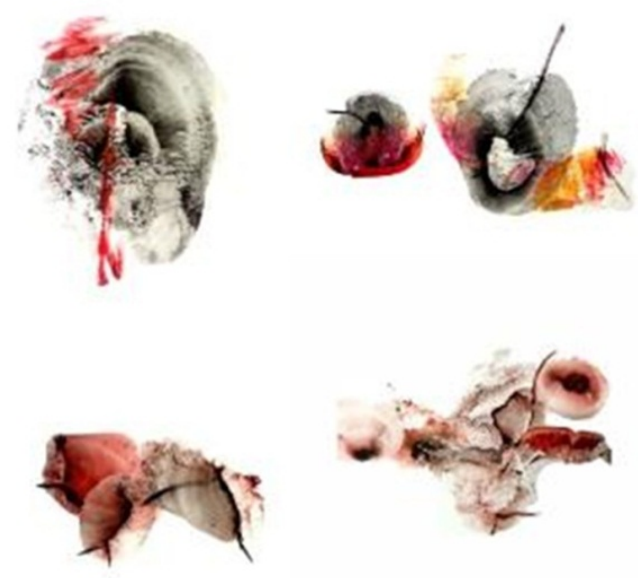

Figure 4. Samples made Recite and Unite Method Source: Personal Work, 2016

\section{Recite and Relate}

The final step is to identify using the Recite \& Relate method (Figure 5). A phenomenon that occurs is a trace that must be identified, in other words a phenomenon is a link between reality (related to distance \& existential space) with an expected presence (related to time), in order to achieve the wholeness of the story of a phenomenon or event. Before reaching the completion of a whole event, can solve a problem or problem then we must first perform this Recite \& Relate stage. If Trace Method is the entrance, then Recite \& Relate this is the

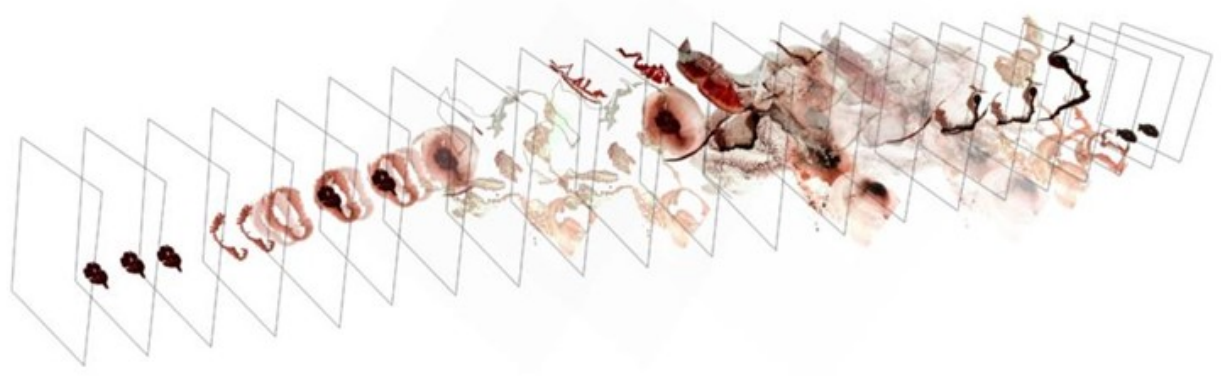

Figure 5. Samples made Recite and Relate Method Source: Personal Work, 2016 


\section{Context Approach}

The environment is certainly not just being a physical limit, but also the existential space intact. To achieve the goal of seeing a certain boundaries of a trails (footprint, hence, etc.) I chose the context of pre-existing and now it is no longer a "prima donna" in their surroundings. The site I chose as the location for this research is the BDNI Centre. A long dormant building that has a lot of advantages to being an element that has no connection with any regularity arising from such a phenomenon. So, $i$ decided to use the area of bdni centre as a place of study and research in to find out about the interiority in the breakdown of a holistic process of a trace (Figure 6).
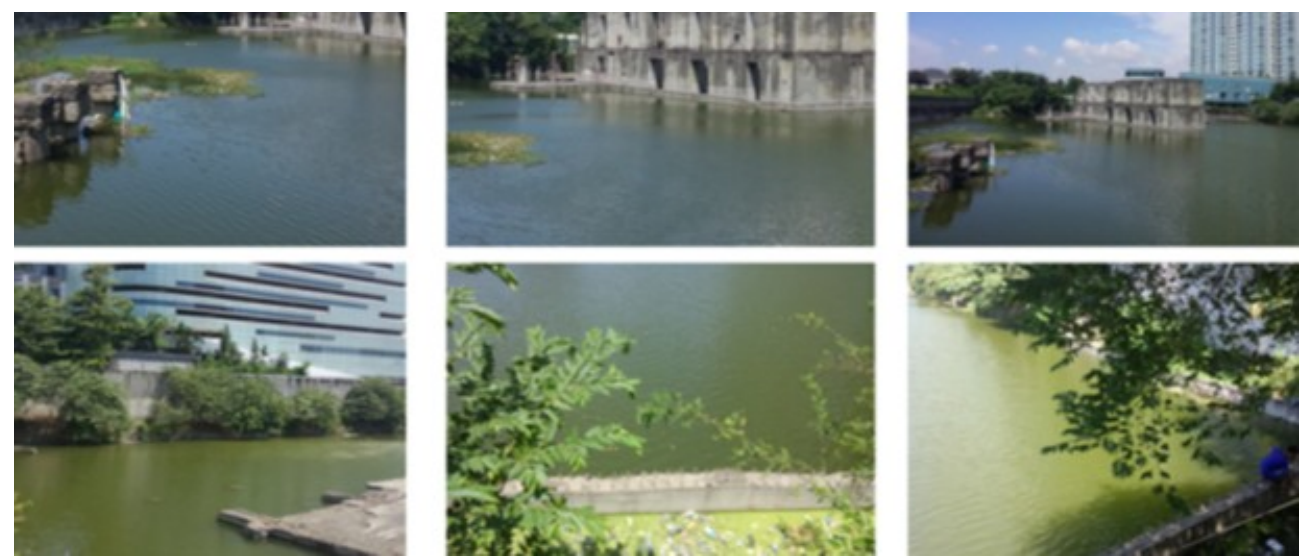

Figure 6. BDNI Centre Documentation, Jakarta Source: Personal Documentatiom, 2016

\section{An Infusion Method}

\section{Re-Create Process}

After going through several methods, studies, and the approach to the context, back again to the theory of autopoietic. When identifying an accident, trace is required as an ingredient to find the integrity of the story. The nature trails in the event are autopoietic. As I've mentioned above in advance that something are autopoietic means is something that actually got and have "other parts" as a unity. "Other parts" which itself has its own network and the process for the sake of achieving wholeness or the holistic process. Through the methods that I've previously mentioned above, can be seen in the existence of "interactions" which tracks only as one small part of the evidence, has and could bring changes that are sustainable, with presenting the interiority. In fact the trace reproduces fragments that produce themselves. 


\section{Plan of Identification with Autopoietic Approaches}

In the planning process, the process of and reading traces, and observing the moment of human beings experiencing their discomfort on their existential space, BDNI centre will be used as a spaces that will be processing limits. Living system unravelling a trail. The scope that will be presented at the limit as a living machine search footprint was by dividing those limits into three spaces, which consists of the input space, processing space, and output space.

\section{Traveling Through The Scene}
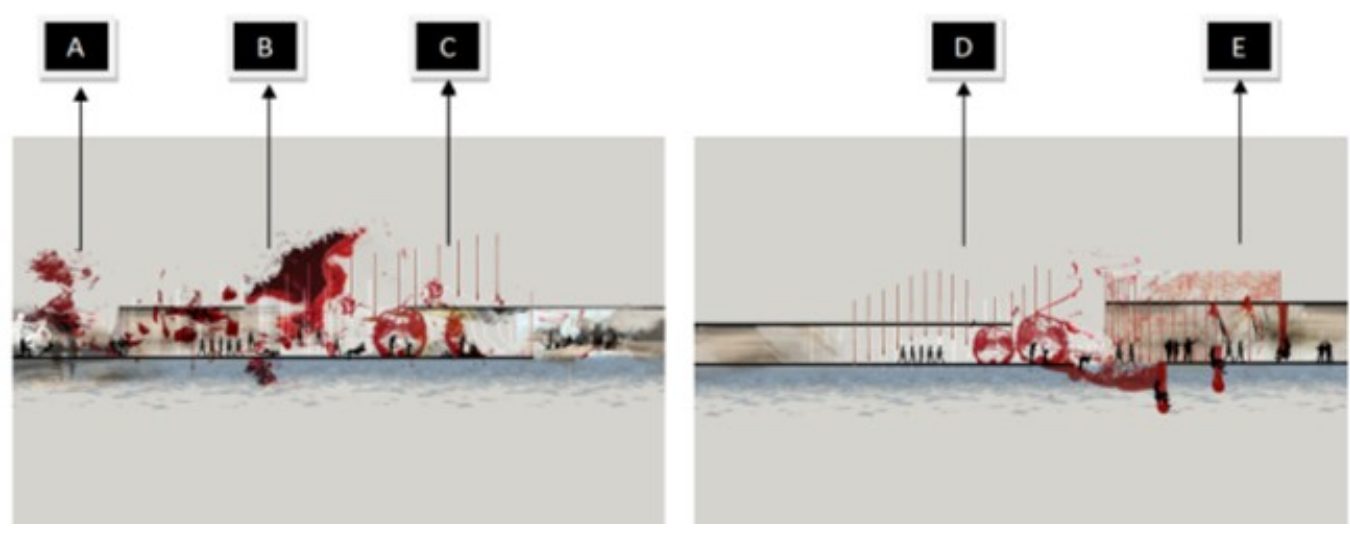

Figure 7. Breaking Down plot diagram, Input-Processing-Output

Source: Personal Work, 2016

Spaces and phenomenon is one unified whole. A holistic concept then the plot is divided into 3 stages space, Input-Processing-Output, this flow looked as well as treating the trail as a single entity. In the plot, this will be the main factor of a criminal case. The main factor of the existence of the plot of the input space of displacement until output is to the movement and displacement, namely the migration of the body from one position to another position, the migration phase identification of a scene to scene. As in the Diagram (Figure 7), the piece of Planning Flow that occurs in Input-Processing-Output space, there are several stages in the program. Phase A and phase B is part of the Input space, phase C and D phase is part of the Processing space, while the phase space E is part of the Output. The identification methods are using Recite \& Unite method. The last phase is the phase space E, the Output space and process, in this space, data will be displayed again thoroughly, and will do an examination and furthermore with a proof more emphasis on recognition of a witness or a suspect (Figure 8 to 10). 


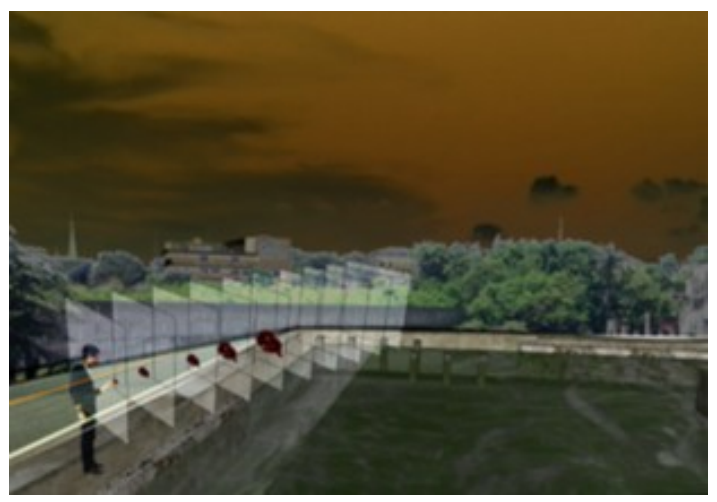

Figure 8. Input program at Input Space. Trail be brought into living machine to be identified Source: Personal Work, 2016

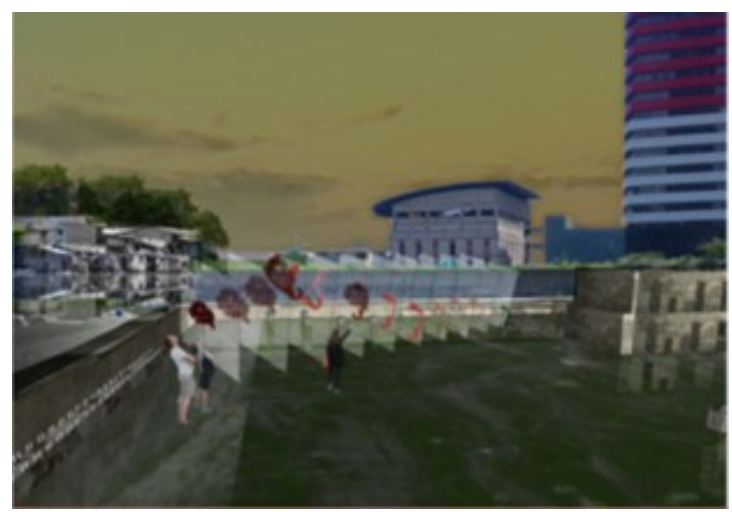

Figure 9. Input Program at Input Space. A stage where the syntax form and content of the material from the trail as the understanding of the existential space

Source: Personal Work, 2016

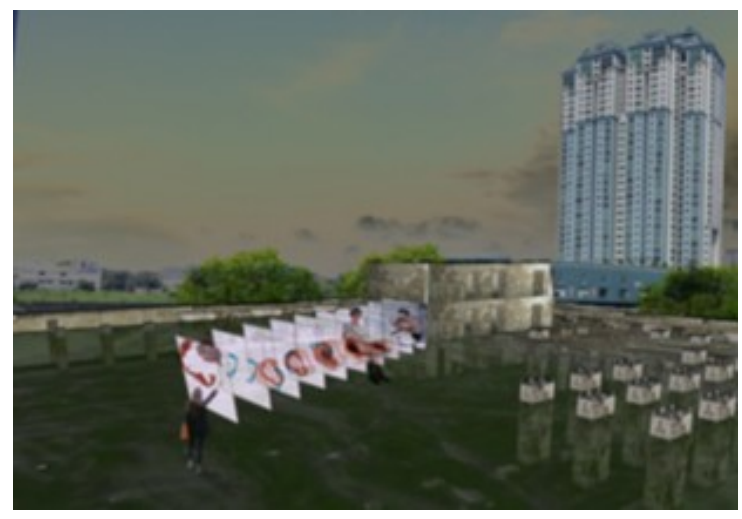

Figure 10. Input program at Input Space. Where the trail started in blow-up and dissected and breakdown into smaller parts

Source: Personal Work, 2016 


\section{Input Space}

Input space on a living system searches these traces is the source of the main sample and research, and other resources required to support the overall process of identification, which are transformed into materials or samples that already sterile and ready processed in the processing space. Samples will be taken and collected by using the method of Trace. All the inputs in the transformation process or dissection are branching new data found on the process in this input space. An activity that will occur in the input spaces are doing observations directly in the area of observation as well as perform data retrieval is needed.

Other stages include:

a. Situational Crime Prevention

Positioned at the entrance area use restrictions in the form of iron and laser to do the selection to anyone who want to come in.

b. Reliabilities Test

This is the area that shows the extent to which the data of observation can be trusted, reliable, and can be used

c. Crime Scene Analysis

Phases in the input information summarizing the basic needs in the formulation of the strategy trail search

d. Observation of the Input

The input data observations, analysis of the sustainability element, data processing, and the analysis results with the planning output analysis results to be presented in the output area

e. Depiction and the placement of the continuity of the element The element must be connected one with the other, at any point

\section{Processing Space}

On the processing space, there will be stages of examination and identification. To understand the search trail completely, thoroughly, holistically. Dissecting the trace and samples obtained into a number of separate parts and put on layers of glass, where the clipped parts will be investigated with some steps with the method of Recite \& Unite.

Space processing is one of the stages to reduce the complexity of the trail, which is considered as part of a small, separated into several parts and systems. This stage also allows the trace identifier and sort out its internal fragments. So the complexity of its separate parts into a detailed and organized. The complexity here will be reduced by using a system of segregation in layer-layer. On the space 
processing is already always involve the process of reduction, i.e. change the complexity that are not organized into organized (Figure 11 to 13)

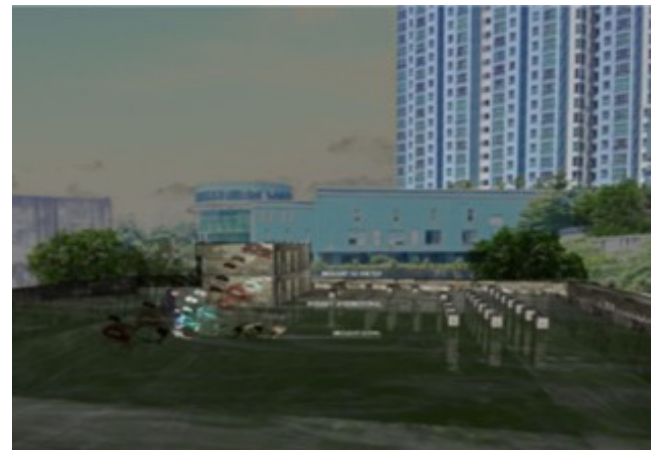

Figure 11. Processing program at Processing Space. A space to process the connection Source: Personal Work, 2016

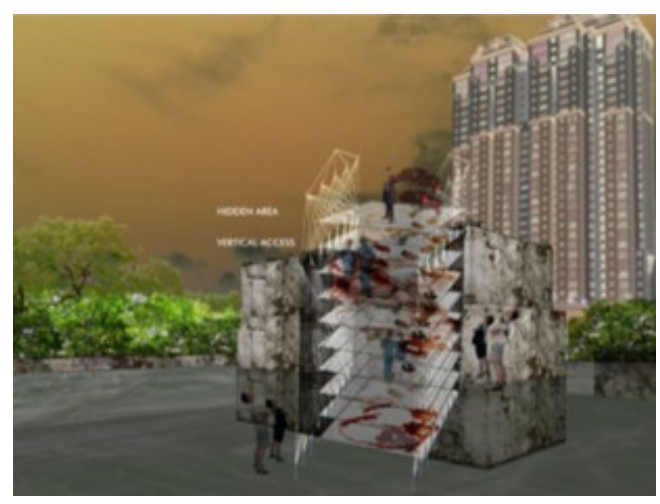

Figure 12. Processing program at Processing Space Identify several phases Source: Personal Work, 2016

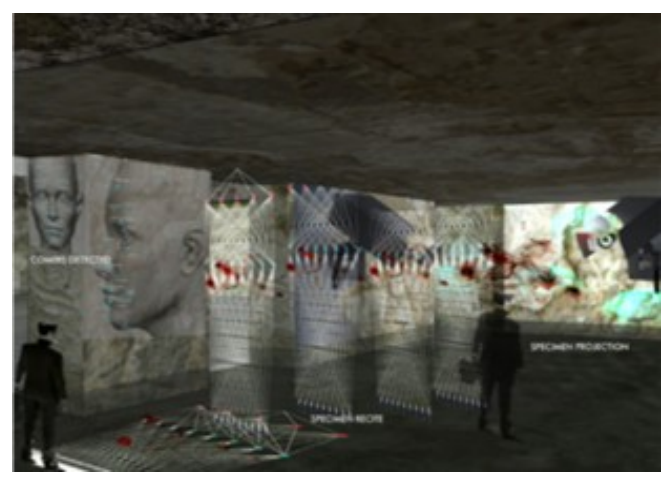

Figure 13. Processing program at Processing Space. See the train in other point of view, to find out the secret Source: Personal Work, 2016 
The purpose of this processing layer flow spaces include:

- Cultivate a trail partially to find connections and continuous

- Identifying the truth through several phases and processes

- Bring and found the interiority through the search

a. Reduce The Complexity of Traces

To reduce the complexity of autopoietic trace, which is considered a small part, the separation must be done according to your needs, so that the trail of evidence of a crime on crime prepared follow-up will be more specific and each layer could be the most important information needed in proofs and searches a case or an accident. Some of the processes that will occur include:

- Dusting. This is an activity re-check the evidence at the Crime Scene

- Handouts. Activities in this handout will not be explaining some of the layer using some analysis data based on scientific technique, but will be a little describes how to detect the presence of glucose, DNA, or any of the small, left behind at the crime scene. A microscope can help the analysis process of a microbiology layer. Where there will be seen elements of microorganisms in details

- Footprints Analysis. Trace of footprints were found, put on a layer, the trail was given a color so that it will leave a clue that is unique and specific to each individual identity.

\section{b. Graceful and Drained}

After reduced the complexity, by using a system of segregation in layer by layer. On the processing space, is already includes the second reduction process, for example, change the complexity that are not organized into organized by using such Graceful and Drained way. By utilizing the water contained in the context. Some of the processes that will occur include:

- Floating Water pressure in the context will be distributed into the burden of any element

- Floating Cover

Floating system will be done in a horizontal plot and lining of the pipe. This system works to prevent the loss of a particle or an important part of each segment, as well as to guard it from contamination

\section{Output Space}

Once the process is completed, the complexity of the traces reduction will found out the indication of crime, along with traces of planning, although only limited 
warning, the next output results will be displayed in a variety of forms in accordance with the needs (Figure 14 to 17).

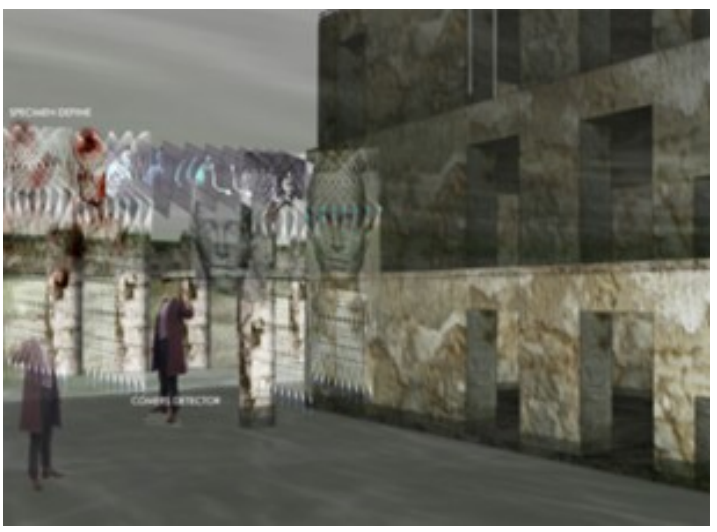

Figure 14. Output program at Output Space Source: Personal Work, 2016

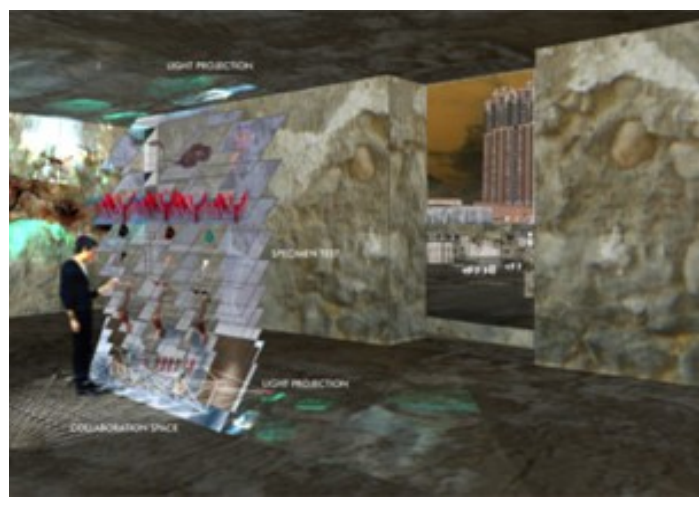

Figure 15. Output program at Output Space Source: Personal Work, 2016

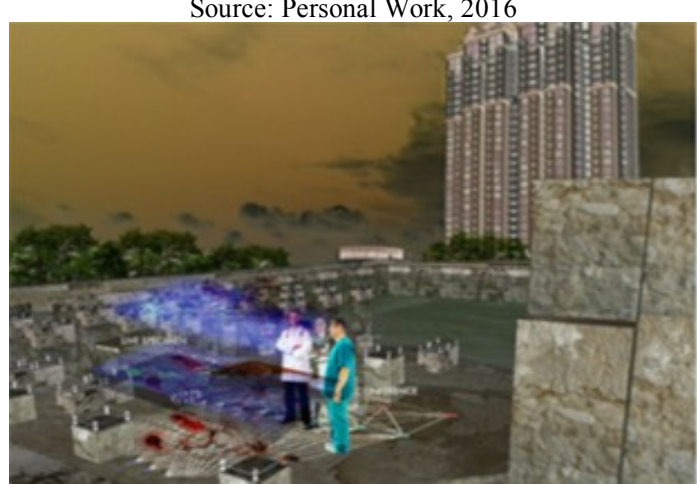

Figure 16. Output program at Output Space Source: Personal Work, 2016 


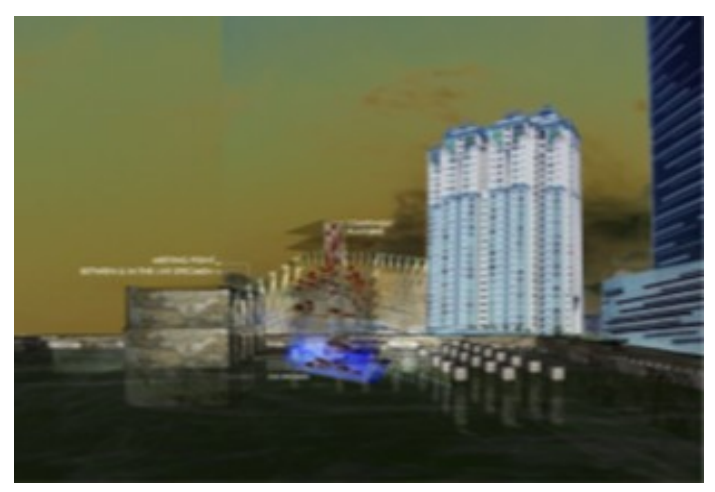

Figure 17. Output program at Output Space Source: Personal Work, 2016

\section{CONCLUSION}

Living in an environment does not make human as an object between the other objects. Public space is an open space that can be accessed by anyone freely, many of the processes actually present when human beings experiencing their discomfort on their existential space, but unconsciously, and only the big parts that appears. Great senses of discomfort are the main reason for human to navigate the process of autopoietic.

To trace some "unknown" parts or "lack of awareness" part of an accident in the past. By the way on the trail traces process, if the traces are present in a point or in anywhere, that lost part, will be part of the spaces, anytime. With the search process with a few methods in the reading process, traces of autopoietic interiorities present and brought back through the separation-partition by using a layer, in order to see the connectedness and the interaction of each segment or small particles that present in traces.

Methods to learn about how the traces of the circuit can be present and bring humans remember the very past time, how humans feel the space by being in a different time, and how time can present. Back again that, when the trail can be present and be a limit, then the interiority are appear. A series of stories will be identified into one whole integrity of the story (Figure 18 and 19). 


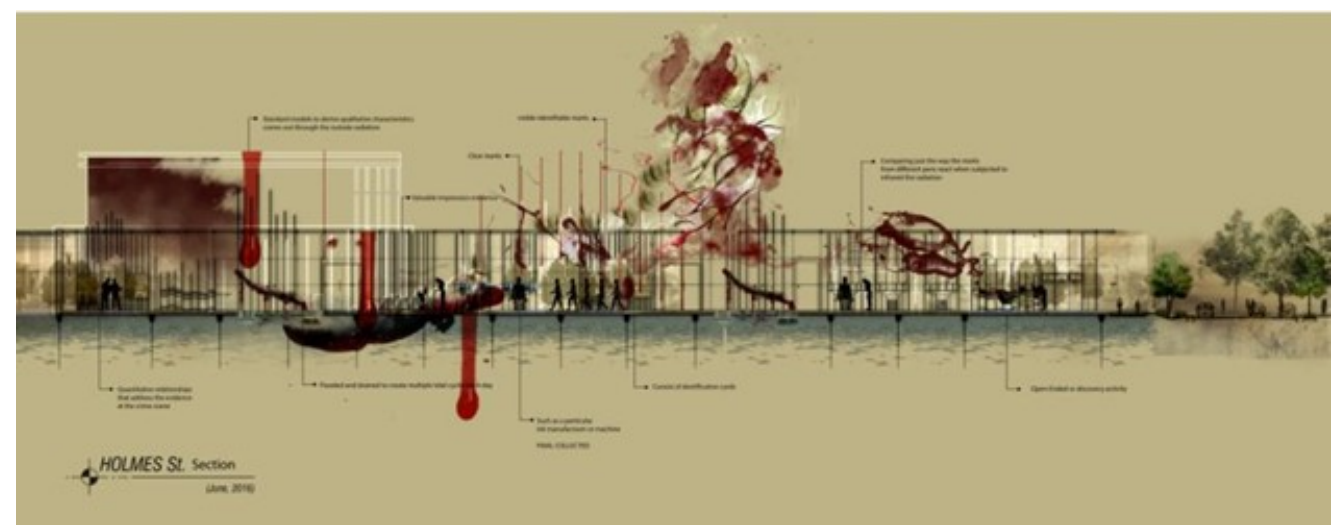

Figure 18. Space Activities, from Input to Output Process Flow (left to right) diagram Source: Personal Work, 2016

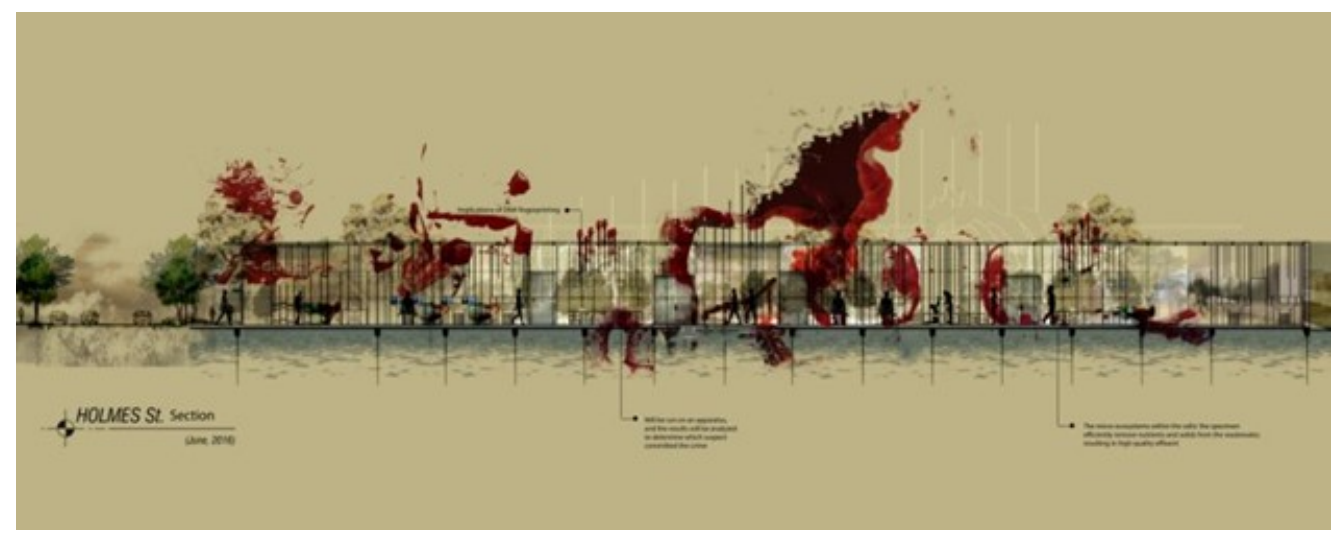

Figure 19. Space Activities, from Input to Output Process Flow (right to left) diagram Source: Personal Work, 2016

The integrity of the story becomes more easy to identify the moment, if we can found the connectedness between three important aspects in the process of identifying, they are the detection of crime, detection of the human itself \& detection of the context which is read by the way human feels the time as and in the space, so that a position already has a third important aspect above, so it will be easier to achieve the ultimate goal of the trail identification process holistically.

The layer system that presented here are the separator between the autopoietic systems of footprint with a system of space their existential space. The layers above serve as a medium of continuity to the process of autopoietic trace. The system determines the configuration limits, scope, or the ability of the system. Surely the limit system that is manifested in the context may be reduced or added in accordance with the needs of the placement of the samples. And each of the layers has a different system and treatment in each of the phases of its (Figure 20 and 21). 


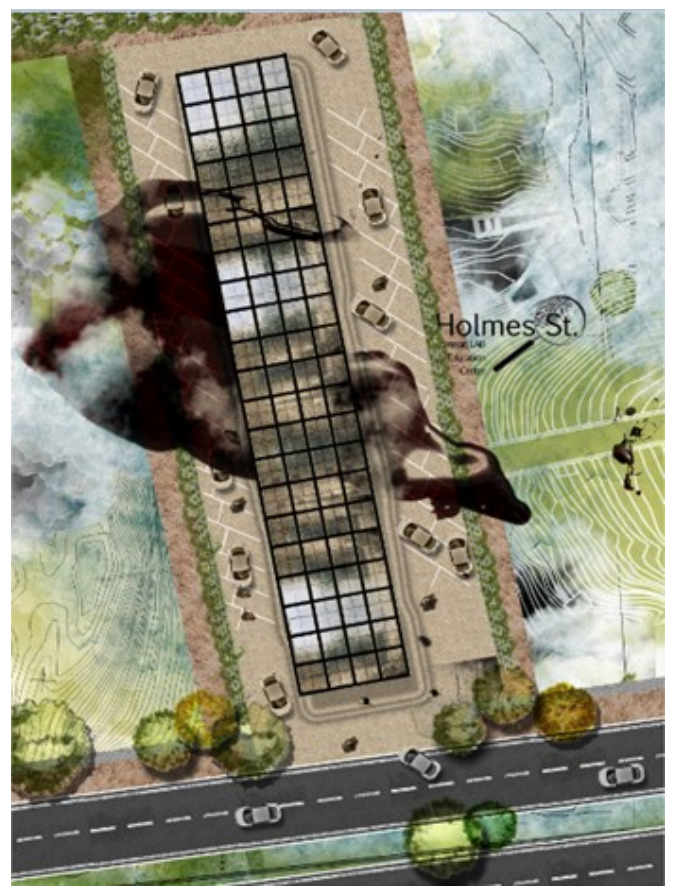

Figure 20. The Site Plan Source: Personal Work, 2016
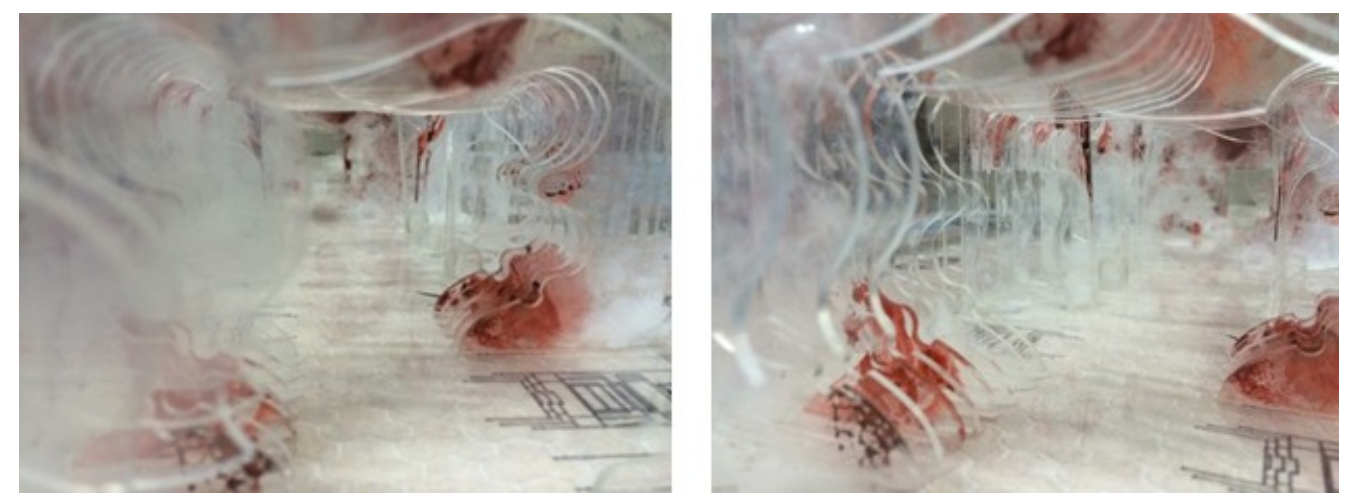

Figure 21. The Maquette

Source: Personal Work, 2016

\section{REFERENCES}

Aeschbacher, P. (2013), "Impossible Totality and Domesticity: Designed Interiors as Monsters", IDEA Journal, Research Institute for Design, Media, and Culture. Baldwin, P.C. (1999). Domesticating the Street: The Reform of Public Space, in Hartford 1850-1930. Ohio State University Press, Columbus. 
Bell, P.A., Greene, T.C., Fisher, J.D., Baum, A. (1996), Environmental Psychology. 4th Edition, Harcourt Brace College Publishers, Sydney.

Caan, S. (2011), Rethinking Design and Interiors, Laurence King Publishing Ltd Gavriloaia, R., Towards A New Mythology of The Interior Design, Pages 205-213.

Glanville, R. (1969), A (Cybernetic) Musing: Design and Cybernetics.

Hollis, Ed. (2013), "Unbecoming”. IDEA Journal, Research Institute for Design, Media, and Culture.

Lang, J. (1991), Design Theory from an Environment and Behaviour Perspective. Chapter 2 in Zube, Ervin H. and Moore, Gary T. (Eds.). 1991. Advances in Environment, Behaviour and Design, Volume 3, Plenum Press, New York.

Lawrence, R.J. (1989), 'Structuralist Theories in Environment-Behaviour-Design Research'. Chapter 2 in Zube, Ervin H and Moore, Gary T. (Eds.). 1989. Advances in Environment, Behaviour and Design, Volume 2, Plenum Press, New York.

Lee, Gini. (2010), "Interior Ecologies", IDEA Journal, Research Institute for Design, Media, and Culture.

Levy-Leboyer, C. (1982), Psychology and the Environment, Sage, London.

Malnar J.M \& Vodvarka F. (2004), Sensory Design, University of Minnesota Press,III Third Avenue South, suite 290, Minneapolis, United States of AmericaMunchen, S. (1997), International Encyclopedia of Systems and CyberneticsCaan,S. (2011). Rethinking Design and Interiors.

Maturana, R.H and Varela, J.F (1974), Autopoiesis and Cognition, The Realization of Living Name of the publisher.

Olkowski, D. and Morley, J. (1999), Merleau-Ponty, Interiority and Exteriority, Psychic Life \& The World, State University of New York Press; First Edition

Sommer, R. (1984), Social Design: Creating Buildings with People in Mind, Prentice Hall Inc., New Jersey.

Stoner J. (2012), Toward a Minor Architecture. MIT Press

Taylor, M. and Preston, J. (1988). INTIMUS, Interior Design Theory Reader, Academy Press

Tuan, Y-F. (2005), Space and Place, The Perspective of Experience, University of Minnesota Press,III Third Avenue South, suite 290, Minneapolis, United States of America.

Zube, E.and Moore, G.T. (Eds.). (1987), Advances in Environment, Behaviour and Design, Volume 1, Plenum Press, New York.

(2011), Places at the Zero Point. Toward a New Interior; an Anthology of Interior Design Theory. 
Alaydrus : HOLMES ST. FORENSIC LAB \& EDUCATION CENTER (IDEA OF INTERIORITY THROUGH THE TRAIL OBSERVATION)

Halaman ini sengaja dikosongkan 